\title{
A review of the LARIAT device: insights from the cumulative clinical experience
}

\author{
Mukta C. Srivastava ${ }^{*}$, Vincent Y. See $^{1}$, Murtaza Y. Dawood ${ }^{1}$ and Matthew J. Price ${ }^{2}$
}

\begin{abstract}
Atrial fibrillation (AF) is the most common arrhythmic disorder world-wide, accounting for $15 \%$ of all strokes. Management of stroke risk in AF is complicated by intolerance of anti-coagulation (AC) therapy and difficulty maintaining therapeutic range in patients treated with warfarin. The left atrial appendage (LAA) is a source of thrombus in AFrelated thrombo-embolic events and surgical LAA exclusion (LAAO) is commonly performed during cardiac surgery in AF patients. Surgical approaches are limited by a high incidence of incomplete closure with a potential for consequent thrombo-embolic events as well as the morbidity of an open-heart procedure. More recently, percutaneous approaches to LAAO have been developed. The LARIAT device is an epicardial LAA exclusion system that enables percutaneous suture ligation of the LAA via combined, pericardial and trans-septal access. The device has 510k Federal Drug Administration (FDA) clearance for soft-tissue ligation and has been studied in canine models in pre-clinical studies as well as published series of clinical experience with LARIAT LAAO. The history, patient selection, procedural technique and complications of LARIAT LAAO are reviewed here. Additionally, insights and procedural improvements that have been elucidated from clinical series and outcomes from the collective experience are discussed. The LARIAT's epicardial approach to LAA ligation is unique compared with other percutaneous LAA exclusion devices, however more data regarding device safety and efficacy is needed for the LARIAT to emerge as an established therapy for stroke prevention in AF.
\end{abstract}

Keywords: Percutaneous left atrial appendage closure devices, Atrial fibrillation, Embolic stroke, Epicardial ligation

\section{Background}

Atrial fibrillation (AF) is the most common arrhythmic disorder worldwide, affecting approximately 2.3 million people in the United States and 4.5 million in the European Union (January et al. 2014). With age, the prevalence and disease burden of AF increases, accounting for $15 \%$ of all strokes and with greater associated morbidity and mortality than non-AF related strokes (January et al. 2014; Connolly et al. 2009). Oral anti-coagulation (AC) is the mainstay of stroke prevention therapy but is complicated by bleeding events and prescribing complexity, with only $50-60 \%$ of patients treated with warfarin consistently in therapeutic range (Go et al. 1999). New oral anti-coagulants (NOACs) such as the direct thrombin inhibitor, dabigatran, and factor Xa inhibitors,

\footnotetext{
*Correspondence: msrivast@medicine.umaryland.edu

${ }^{1}$ University of Maryland School of Medicine, 110 S. Paca Street; 7N-121,

Baltimore, MD 21201, USA

Full list of author information is available at the end of the article
}

rivaroxaban and apixaban, provide consistent $\mathrm{AC}$ compared with Coumadin but are limited by bleeding complications, expense and inability to expeditiously reverse these agents during an acute bleeding event (Connolly et al. 2009; Patel et al. 2011; Granger et al. 2011). These challenges have led to a focus on alternate therapies to reduce stroke risk in patients with $\mathrm{AF}$.

The left atrial appendage (LAA) has a narrow-orifice with a tubular, trabeculated structure that fibrillates rather than contracts in $\mathrm{AF}$, resulting in blood stasis and predisposition to thrombus formation (Al-Saady et al. 1999; Kanmanthareddy 2014). In a meta-analysis of 23 studies of AF patients, thrombus, when present, was localized to the LAA in $91 \%$ of patients with non-valvular AF. The implication of the LAA as a primary source of thrombus for thrombo-embolic events in non-valvular AF has made it a veritable target for stroke reduction.

Surgical LAA exclusion by excision or ligation of the LAA, when combined with the Cox-Maze procedure, has

\section{望 Springer}

(c) 2015 Srivastava et al. This article is distributed under the terms of the Creative Commons Attribution 4.0 International License (http://creativecommons.org/licenses/by/4.0/), which permits unrestricted use, distribution, and reproduction in any medium, provided you give appropriate credit to the original author(s) and the source, provide a link to the Creative Commons license, and indicate if changes were made. 
demonstrated proficiency in reducing subsequent stroke risk (Bonow et al. 2008; Cox et al. 1999). Notably, a $36 \%$ incidence of incomplete exclusion with surgical ligation alone has been observed and associated with thrombus formation in the partially excluded LAA as well as subsequent thrombo-embolic events (Katz et al. 2000). The flaccid state of the LAA on cardiac bypass and proximity of the circumflex artery to the base of the LAA, have been proposed etiologies of sub-optimal success with surgical approaches. Excision of the LAA provides more consistent results and the 2014 AHA/ACC/HRS Guidelines for the management of atrial fibrillation provide a Class IIB/Level of Evidence C, recommendation for surgical excision of the LAA in patients undergoing cardiac surgery (January et al. 2014). However, surgical excision remains limited by the morbidity of an open-heart procedure and lack of robust efficacy data. Surgical experience has inspired and informed the development of percutaneous left atrial appendage occlusion (LAAO) devices. The LARIAT ligation system is currently the most studied percutaneous epicardial LAAO device.

\section{LARIAT ligation}

Device development

The LARIAT device was developed by a cardiothoracic surgeon and has United States Federal Drug Administration (US FDA) 510k clearance for the indication of softtissue approximation with greater than 2000 implants world-wide for LAA ligation (Price and Gibson 2014). A second generation of the device accommodating larger LAAs is also now commercially available. The LARIAT system accomplishes percutaneous delivery of a suture that snares the LAA epicardially, at its os, via trans-septal and pericardial access. Pre-clinical canine studies demonstrated angiographic LAA exclusion utilizing LARIAT LAAO, confirmed by macroscopic evaluation and showed progressive LAA atrophy and endothelialization of the LAA orifice in a time-dependent manner from ligation (Lee et al. 2010). The utility of an endoluminal, balloon, placed at the os of the LAA to guide LARIAT snare placement and prevent suture slippage was elucidated in an animal trial as well (Singh et al. 2010). Subsequent clinical trials have led to the use of LARIAT ligation most widely for an off-label indication of left atrial appendage ligation for stroke reduction.

\section{Patient selection}

Patient selection (Table 1) for the LARIAT LAAO is guided by the initial safety and feasibility trial completed by Bartus et al. and by experiences published by early operators (Price and Gibson 2014; Stone et al. 2013; Bartus et al. 2013; Massumi et al. 2013). Bartus et al. included: AF patients with a CHADS ${ }^{2}$ score of $\geq 1$ with one of: (1) contraindication to AC, including gastrointestinal, intra-cerebral, urologic or pulmonary bleeding, (2) cerebrovascular accident (CVA) despite adequate AC or (3) indication for 'triple-therapy' with aspirin, thienopyridine and $\mathrm{AC}$ with high bleeding risk (Bartus et al. 2013).

Contraindications include prior pericarditis or pericardiotomy and thoracic radiation, as pericardial adhesions complicate pericardial access required for LARIAT LAAO. Due to appendage manipulation during the procedure, active thrombus within the LAA is also contraindicated. Additionally, Bartus et al. excluded patients with a myocardial infarction within 3 months, thromboembolic event within 30 days, New York Heart Association (NYHA) Class IV heart failure and left ventricular ejection fraction $<30 \%$.

LARIAT candidates undergo an anatomical evaluation with a cardiac-gated, computed tomography (CT) scan with contrast and 3D image reconstruction to evaluate for anatomical exclusions that preclude successful device advancement. These include: (1) LAA width $>40 \mathrm{~mm}$, (2) superiorly oriented LAA with the apex directed behind the pulmonary artery (PA), (3) multi-lobed LAA in which lobes are oriented in different planes exceeding $40 \mathrm{~mm}$, and (4) posteriorly rotated heart.

\section{Procedure}

The LARIAT procedure has been extensively detailed as have recommendations to minimize complications and optimize outcomes (Lee et al. 2010; Singh et al. 2010; Bartus et al. 2011, 2013; Valderrabano 2014; Price 2014; Koneru et al. 2014). LARIAT LAAO typically takes place in a cardiac catheterization laboratory (CCL), electrophysiology laboratory (EPL) or hybrid operating room and is implanted by electrophysiologists and interventional cardiologists under general anesthesia with transesophageal echocardiography (TEE) guidance. The procedure requires optimal pericardial access described in Figs. 1 and 2 as well as trans-septal access. Ligation occurs with advancement of the LARIAT device via the pericardial sheath over a rail system created by the attached endocardial and epicardial guidewires, followed by snare-capture of the LAA.

A pericardial drain is typically left in place and removed the following day if output is minimal. Patients are discharged $24-48 \mathrm{~h}$ after uncomplicated implantation and surveillance TEE is performed at 4-6 weeks postimplant. Pain management approaches include Tylenol as well non-steroidal anti-inflammatory agents. Scheduled colchicine for 2 weeks following LARIAT ligation has been effective in reducing the incidence of post-procedural pericarditis and pain. Anti-platelet and AC regimens following LARIAT ligation in published experience are variable with some patients continued on AC therapy 


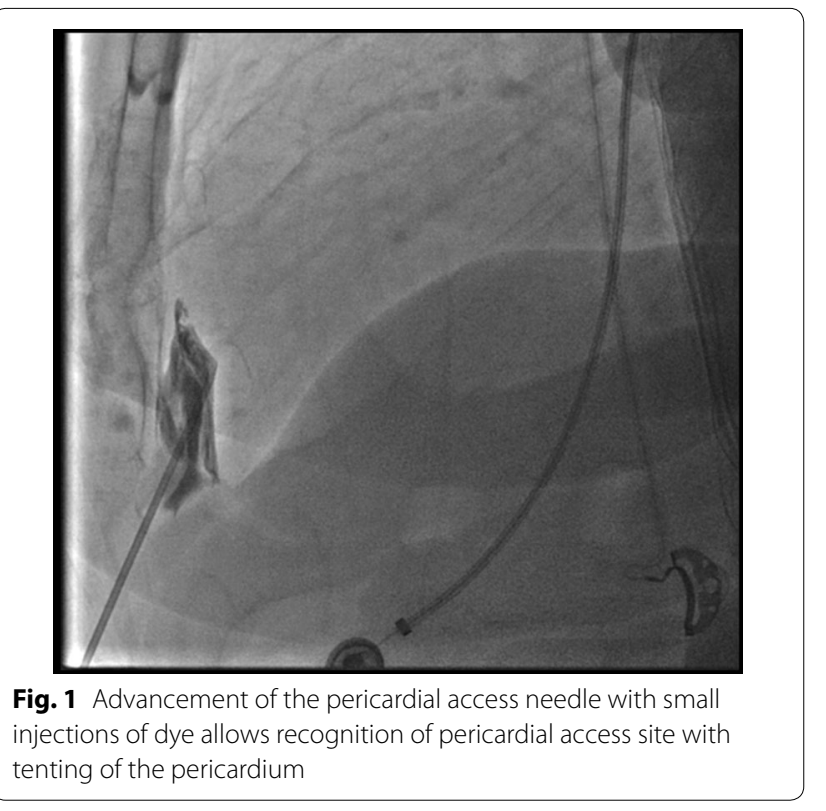

if tolerated, others treated with Aspirin or Plavix or both for a period of time (Koneru et al. 2014).

\section{Imaging}

Laura et al. have detailed the role of multi-modality imaging during LARIAT ligation (Laura et al. 2014). A contrast, cardiac-gated CT is utilized to plan pericardial access and provides information regarding anatomical features such as pulmonary artery enlargement, large xiphoid process or tight retrosternal space and delineates the course of the phrenic nerve and internal mammary artery. CT can also exclude thrombus pre-procedurally as well as indicate the presence of accessory LAAs or diverticula (Ismail et al. 2015). TEE confirms the absence of LAA thrombus, guides placement of the snare at the LAA os by allowing endocath balloon visualization and provides surveillance for pericardial effusion development during the procedure (Fig. 3). TEE and LA angiography are utilized for confirmation of closure, to assess for residual jets immediately post-procedure and to guide further suture tightening (Fig. 4).

\section{Peri-procedural complications}

Complications during LARIAT LAAO can occur during trans-septal, pericardial or venous access as well as during LARIAT delivery. Technical approaches to prevent LARIAT LAAO complications are summarized in Table 2 (Price 2014).

Pericardial effusion and tamponade from RV puncture or abrasion during sheath advancement can complicate pericardial access. Coronary or epigastric artery laceration, trauma to intra-abdominal organs and pleural puncture have also been observed with LARIAT LAAO but should be avoidable with review of pre-procedural CT (Price and Gibson 2014; Stone et al. 2013). Utilizing a micro-puncture needle for pericardial access may mitigate the risk of significant RV laceration. When encountered, adhesions should lead to consideration for aborting ligation given low likelihood of procedural success in this setting and higher risk of complication. Effusions should be promptly
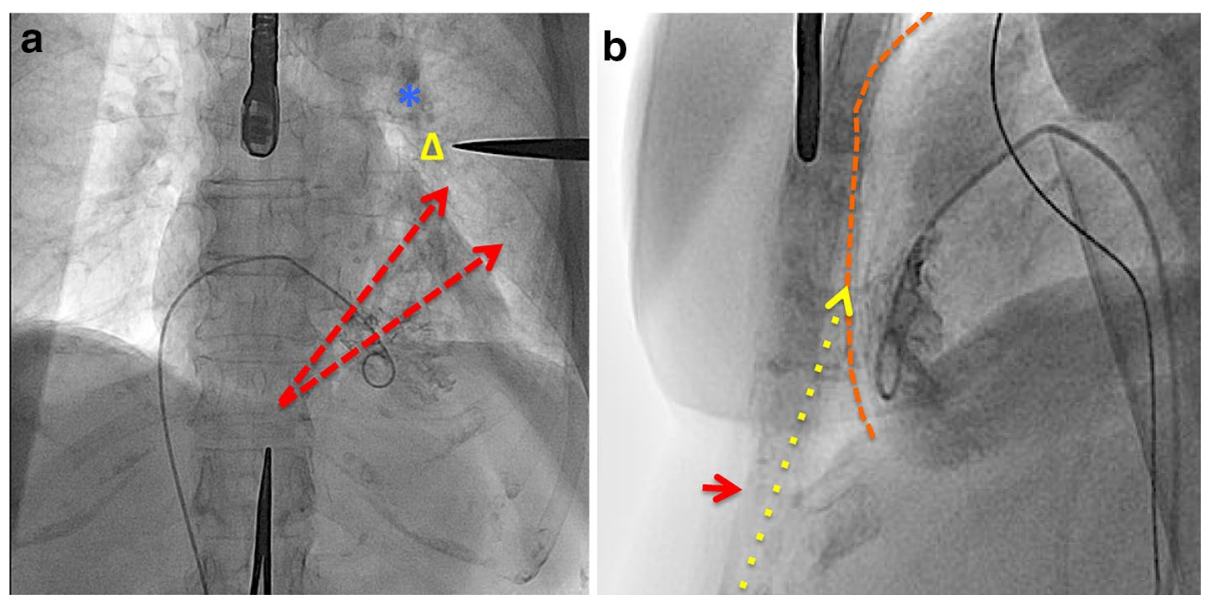

Fig. 2 Pericardial access planning in the AP and LL projections. a In the AP projection, Kelley clamps are placed below the sub-xiphoid process and at the likely position of the LAA $(\Delta)$ based on the position of the PA $(*)$. The ideal trajectory of trans-septal sheath placement is lateral to the LAA in the region between the dashed red arrows. $\mathbf{b}$ In the LL view, the pericardial silhouette (orange dashed line) can be approximated by performing a right ventriculogram outlining the RV endocardium. The anterior pericardium is entered following the tract of the dotted yellow arrow. The xiphoid process tip is noted at the short red arrow 

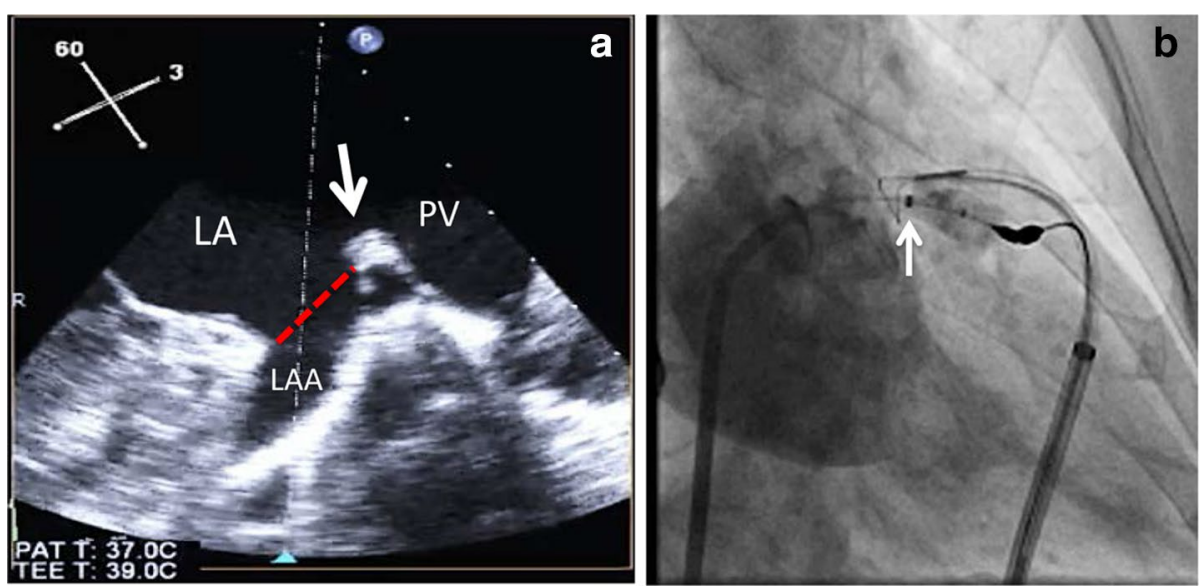

Fig. 3 a The dashed line indicates the desired ligation site, just inferior to the Coumadin ridge (arrow). b The proximal end of the balloon is positioned at the LAA orifice under TEE guidance. The radio-opaque marker at the proximal end of the balloon (arrow) guides advancement of the LARIAT system over the LAA os under fluoroscopy; PV pulmonary vein

Table 1 LARIAT LAAO patient selection (Bartus et al. 2013)

\begin{tabular}{|c|c|c|}
\hline Clinical inclusion recommendations & Clinical exclusion recommendations & Anatomical exclusion recommendations \\
\hline Atrial fibrillation with $\mathrm{CHADS}^{2}$ score $\geq 1$ & $\begin{array}{l}\text { History of prior cardiac surgery } \\
\text { Myocardial infarction within } 3 \text { months }\end{array}$ & LAA width $>40 \mathrm{~mm}$ \\
\hline Contraindication to AC therapy including: & History of pericarditis & $\begin{array}{l}\text { Superiorly oriented LAA with the LAA apex } \\
\text { directed behind the pulmonary trunk }\end{array}$ \\
\hline Gastrointestinal bleeding & History of thoracic radiation & $\begin{array}{l}\text { Multi-lobed LAA in which lobes are oriented in } \\
\text { different planes exceeding } 40 \mathrm{~mm}\end{array}$ \\
\hline Intra-cranial bleeding & Pectus Excavatum & Posteriorly rotated heart \\
\hline Urologic bleeding & Thromboembolic event within 1 month & \\
\hline Pulmonary bleeding & New York Heart Association Class IV heart failure & \\
\hline Recurrent CVA despite adequate $\mathrm{AC}$ therapy & Left ventricular function $<30 \%$ & \\
\hline \multicolumn{3}{|l|}{$\begin{array}{l}\text { Requirement for aspirin, thienopyridine therapy } \\
\text { and AC therapy with high-bleed risk }\end{array}$} \\
\hline Intolerance to AC therapy & & \\
\hline
\end{tabular}

INR international normalized ratio, CVA cerebrovascular accident
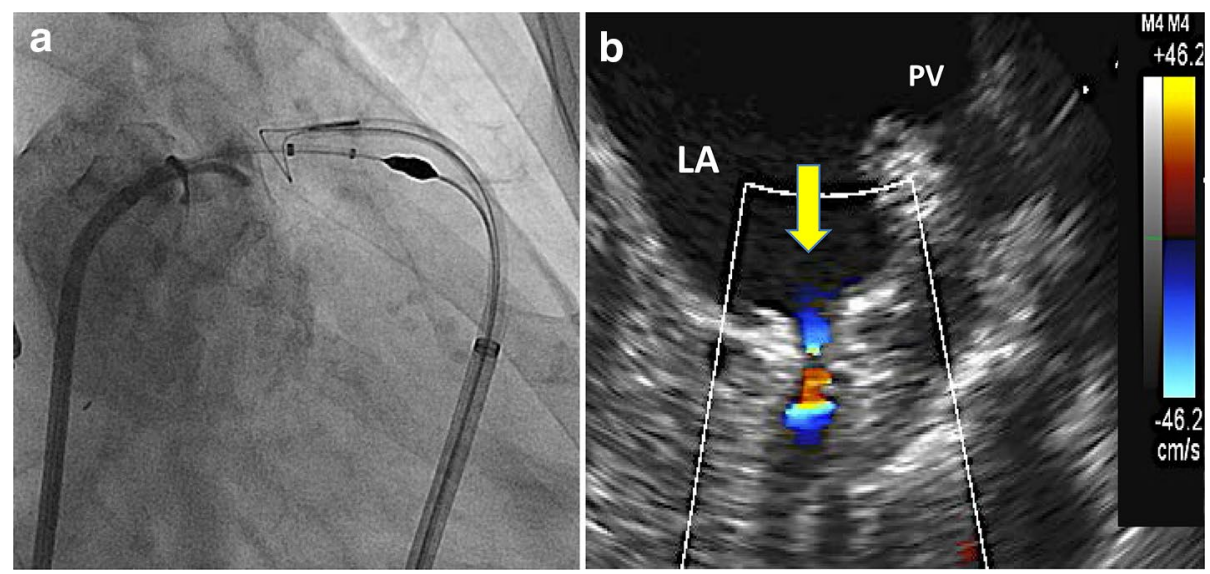

Fig. 4 a $L A$ angiography post $L A R I A T L A A O$ without flow into the snared $L A A \mathbf{b}$ TEE demonstrating residual $1 \mathrm{~mm}$ jet of flow into the ligated $L A A$ (yellow arrow) 
Table 2 Potential prevention strategies for procedural complications of LARIAT LAAO (Price 2014; Keating et al. 2014)

\begin{tabular}{|c|c|c|}
\hline Complication & Cause & Preventative strategy \\
\hline Pericardial effusion & $\begin{array}{l}\text { Initial TSP } \\
\text { Guide wire or catheter trauma to LAA after TSP } \\
\text { Manipulation of delivery system in pericardium } \\
\text { Pericardial access }\end{array}$ & $\begin{array}{l}\text { TEE guidance } \\
\text { Avoidance of severe IAS tenting } \\
\text { Advancement of trans-septal sheath dilator into LAA under } \\
\text { fluoroscopy over } 0.32^{\prime \prime} \text { wire with distal curve on coronary } \\
\text { wire } \\
\text { TEE surveillance for RV compression with sheath advance- } \\
\text { ment to avoid RV abrasion } \\
\text { Micro-puncture access needle } \\
\text { Placement of a'bail out' wire in the pericardium for quick } \\
\text { pericardial drain placement }\end{array}$ \\
\hline LAA laceration or perforation & LARIAT advancement and deployment & $\begin{array}{l}\text { Cognizance of endocardial and epicardial wire forces on } \\
\text { LAA } \\
\text { Minimization of LARIAT delivery system prolapse onto LA } \\
\text { Careful suture tightening }\end{array}$ \\
\hline Procedural stroke & $\begin{array}{l}\text { LAA thrombus } \\
\text { Insufficient AC } \\
\text { Air embolus }\end{array}$ & $\begin{array}{l}\text { Careful baseline TEE } \\
\text { Close AC monitoring } \\
\text { Careful flushing of trans-septal sheath }\end{array}$ \\
\hline Vascular complications & $\begin{array}{l}\text { Hematoma, arterio-venous fistula, pseudoaneurysm, } \\
\text { bleeding, hematoma }\end{array}$ & Careful technique with ultrasound guidance as needed \\
\hline
\end{tabular}

$T S P$ trans-septal puncture, IAS inter-atrial septum, $R V$ right ventricle

treated with drainage and reversal of $\mathrm{AC}$ as well as consideration for surgery and can be managed anticipatorily with placement of an extra 'bail out' wire in the pericardial space to provide pericardial access for expedited drainage of a large effusion (Price 2014). Late pericardial effusions may develop and are hypothesized to result from inflammation related to LAA necrosis. Late pleural effusions have also been noted and may be transudative or exudative and potentially represent volume retention from reduced atrial natriuretic peptide (ANP) release after LAA ligation (Gunda et al. 2015).

Traction forces on the LA during LARIAT advancement and suture tightening can lead to LAA laceration or perforation and need for surgical rescue. Keating et al. reported LA laceration and cardiac tamponade requiring surgical intervention in 3 of 6 LARIAT ligations performed at their center (Keating et al. 2014). Reducing catheter prolapse onto the LA, particularly when the LA is enlarged, is a recommended preventative practice for LA or LAA laceration. Deployment of the LARIAT at a position with sufficient laxity such that the appendage orifice is recreated by proximal LAA tissue results in lesser traction on neighboring LA tissue. LAA perforation can occur during connection of the endo- and epi- wires, when tension imposed on the friable LAA can cause the epicardial wire to perforate. While prompt LARIAT deployment is a definitive treatment for LAA laceration or perforation, surgical readiness and a low threshold for surgical evaluation of ongoing pericardial output is recommended to avoid rapid decompensation.

\section{Clinical experience and outcomes}

Results of the published clinical experience with the LARIAT device with greater than ten patients are reviewed in Tables 3, 4 and cumulative event rates of series only closed-chest ligation are summarized in Table 5.

The first-in-man feasibility study of the LARIAT device evaluated 13 patients undergoing LARIAT ligation either during open-heart surgery or in a closed-chest fashion. Twelve of 13 patients in this series had successful LAA ligation with 1 patient in whom the procedure was terminated due to lack of adequate echocardiographic guidance for snare advancement. Notably, a patient with pectus excavatum required a thoracoscopic procedure for device removal due to sternal compression (Bartus et al. 2011).

Bartus et al. subsequently published experience with LARIAT ligation in 92 patients from a single center, where ligation was successfully completed in 85 of 92 or $93 \%$ of subjects. At 1-year follow-up, 65 patients underwent follow-up TEE with all patients having $<5 \mathrm{~mm}$ leak. Notably, $55 \%$ of the patients in this series were continued on AC therapy (Bartus et al. 2013).

Massumi et al. reported the first series of LARIAT ligation performed in the (US) in a single-center report of 20 patients. All attempted ligations were successful however peri-procedurally, 1 patient required surgical intervention for RV perforation and 1 patient was treated with pericardiocentesis for tamponade physiology. All 17 patients undergoing follow-up TEE at a mean of $96 \pm 77$ days had persistent LAA occlusion. However, in 6 of 17 patients, a small pouch was noted at the LAA os, containing smooth muscle tissue in 5 patients 


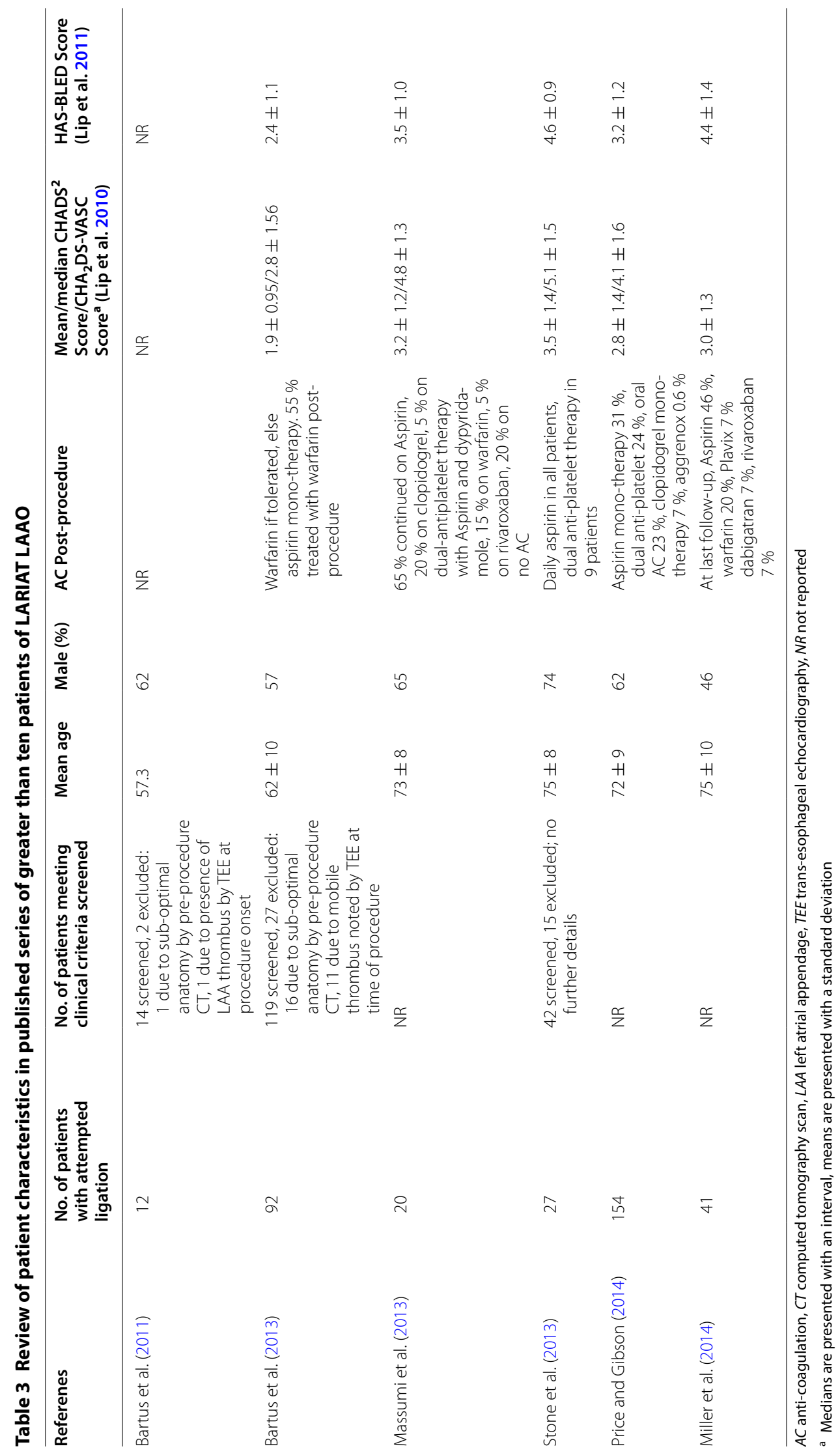




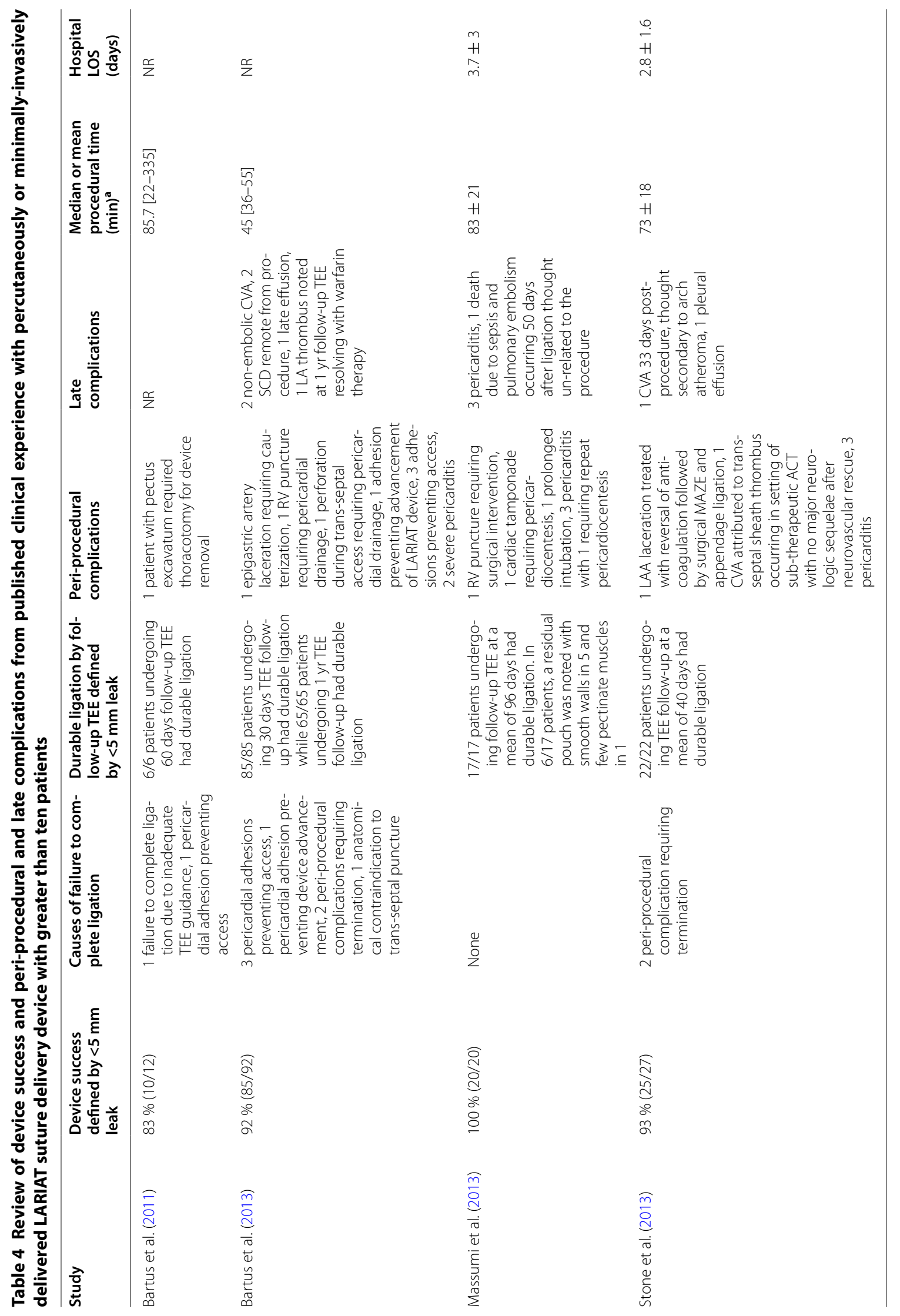




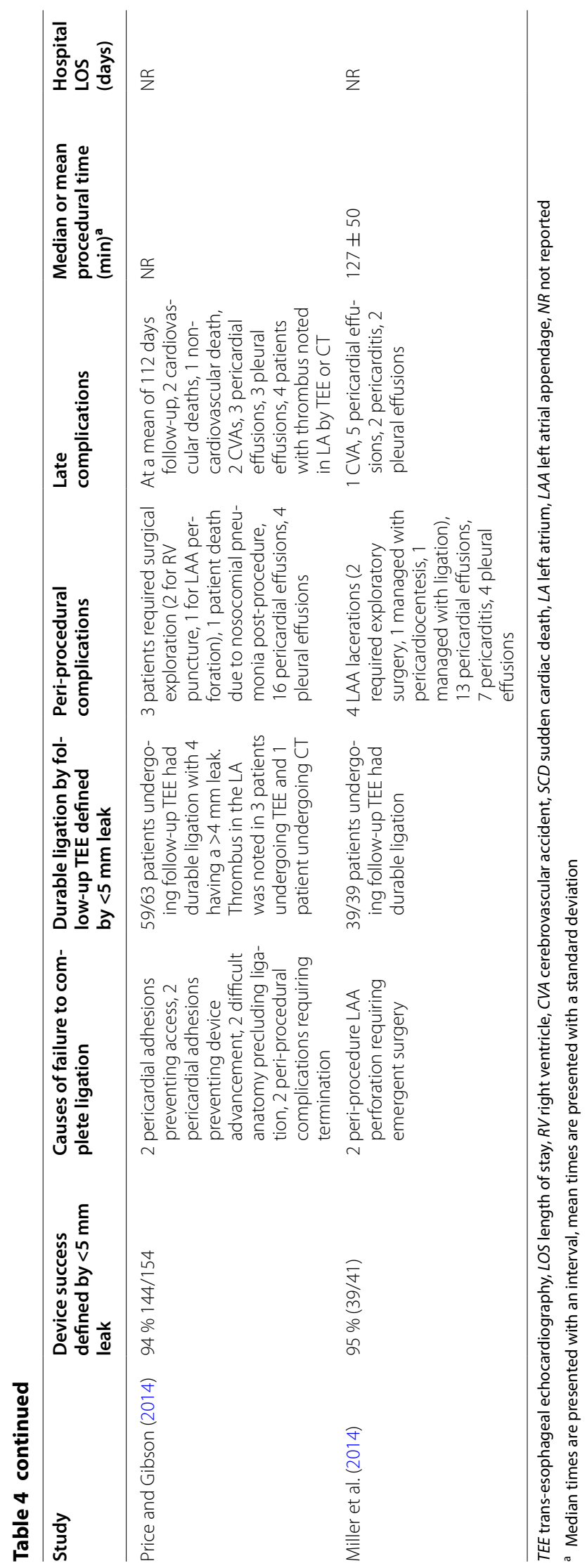


Table 5 LARIAT LAAO success and durability and procedural and late adverse events from published series with greater than 10 patients and closed-chest ligation ${ }^{1}$ (Price and Gibson 2014; Stone et al. 2013; Bartus et al. 2013; Massumi et al. 2013; Miller et al. 2014)

\begin{tabular}{|c|c|}
\hline & Number of patients \\
\hline Device success ${ }^{\mathrm{a}}$ & $313 / 334(94 \%)$ \\
\hline Device durability ${ }^{\mathrm{b}}$ & $222 / 226(98 \%)$ \\
\hline Procedural adverse events ${ }^{c}$ & $64 / 334(14.7 \%)$ \\
\hline Death & $1 / 334(0.3 \%)$ \\
\hline LAA laceration & $6 / 334(1.8 \%)$ \\
\hline CVA/TIA & $1 / 334(0.3 \%)$ \\
\hline Significant pericardial effusion ${ }^{d}$ & $25 / 334(7.5 \%)$ \\
\hline Complication with surgical intervention & $8 / 334(2.4 \%)$ \\
\hline Pericarditise & $15 / 180(8.3 \%)$ \\
\hline Pleural effusion & $8 / 334(2.4)$ \\
\hline Late adverse events & 33/334 (9.9\%) \\
\hline Death & $6 / 334(1.8 \%)$ \\
\hline CVA/TIA & 6/334 (1.8\%) \\
\hline Pleural effusion & $6 / 334(1.8 \%)$ \\
\hline Pericardial effusion & 10/334 (3.0 \%) \\
\hline Thrombus in LA or LAA by TEE/CT & $5 / 227(2.2 \%)$ \\
\hline
\end{tabular}

a Successful deployment of device with $<5 \mathrm{~mm}$ leak by TEE/CT

b LAA leak $<5 \mathrm{~mm}$ by last follow-up TEE/CT in those whom follow-up imaging available

c Events occurring prior to discharge and not including pericarditis

d Effusions requiring pericardiocentesis or vasopressor therapy

e Price et al. did not provide pericarditis rate

and pectinate muscles in one patient. Involution of the excluded LAA was noted in 3 patients in whom followup CT imaging was performed (Massumi et al. 2013).

Stone et al. reported a series of 27 US patients, selected from 42 patients being evaluated for LAAO that underwent LARIAT ligation, with 25 of 27 having successful ligation. One peri-procedure stroke was attributed to a sub-therapeutic ACT with thrombus noted on the transseptal sheath. All 22 patients completing follow-up TEE at a mean of 45 days had durable ligation (Stone et al. 2013).

The largest US LARIAT experience studied 154 consecutive patients undergoing LAA ligation at eight centers. Device success, defined as device deployment with $<5 \mathrm{~mm}$ residual leak by TEE, was achieved in $94 \%$ of patients. Major bleeding occurred in $9 \%$ of patients, and peri-procedural pericardial effusion in $16 \%$. Despite similar device success rates as other series, a higher rate of late-leak (20\%) and LA thrombus (4.8\%) was noted in follow-up. Of note, the patients included in this study were older and had more co-morbidities than the initial single center study of Bartus et al. (Price et al. 2014).
Miller et al. reported on an additional 41 consecutive patients undergoing LARIAT ligation with 39/41 having procedural success. A high rate of pericardial effusions requiring pericardiocentesis post-procedurally was noted (20\%), which authors attributed to operators in this series not maintaining a pericardial drain post-procedurally. Seven percent of patients required thoracentesis for late pleural effusions. Authors also noted a high rate of LAA perforation, with 2 of 4 patients with this complication requiring surgical treatment. All 4 patients with LAA perforation required multiple attempts to position the LARIAT snare, suggesting that in cases of challenging anatomy, advancement should be attempted when endocardial and epicardial wire alignment is optimal and aborted after a limited number of attempts to avert laceration and perforation (Miller et al. 2014).

Gafoor and authors evaluated the safety and efficacy of LAAO with a number of occlusion devices in a cohort of 75 octogenarians. Procedural success was noted in all 4 patients undergoing LARIAT exclusion, with no acute adverse safety events and an average hospital length of stay of 2.5 days. At 1-year, 1 LARIAT patient had an embolic stroke with thrombus originating from an incompletely ligated lobe of the appendage (Gafoor et al. 2014).

Patel et al. evaluated the compassionate use of LARIAT ligation in 9 patients who were precluded based on appendage morphology and size. Their analysis showed a LARIAT deployment success rate of $78 \%$ utilizing strategies such as using the magnet-tipped endowire to straighten the LAA to reduce circumference and utilizing the endocath balloon to suction from the LAA, effectively reducing LAA volume (Patel et al. 2015).

The FDA's Manufacturer and User Facility Device Experience (MAUDE) reports 38 LARIAT-related adverse events from January 2012 to March 2015, including 31 instances requiring emergent sternotomy for bleeding complications following LARIAT attempts, 4 deaths and 1 episode of unexplained VT linked to myocardial scar after LARIAT ligation (Fig. 5). LA/LAA laceration or perforation accounted for $66 \%$ of reported events, with LA/ LAA laceration most commonly resulting from multiple attempts at advancing the suture delivery system over the LAA while perforation most commonly resulted from endowire trauma.

\section{Discussion}

Several features distinguish the LARIAT LAAO system. Compared with percutaneous endocardial LAAO devices such as the WATCHMAN (Boston Scientific Corporation, Natick, Massachusetts) and Amplatzer (St. Jude Medical, Inc., Saint Paul, Minnesota), systems, the LARIAT approach is epicardial, with only a polyester 


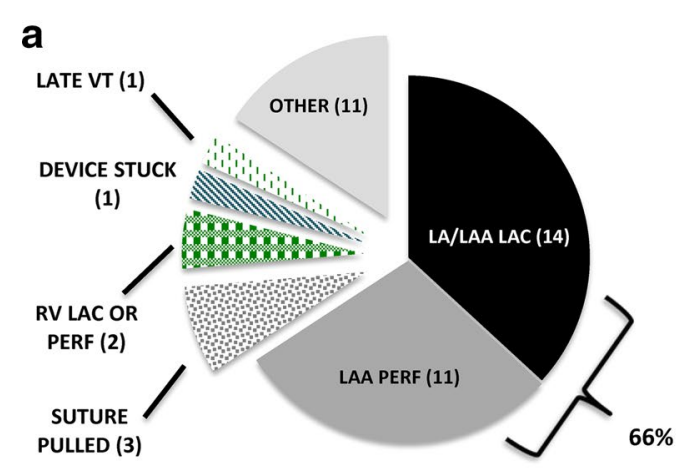

\section{b}

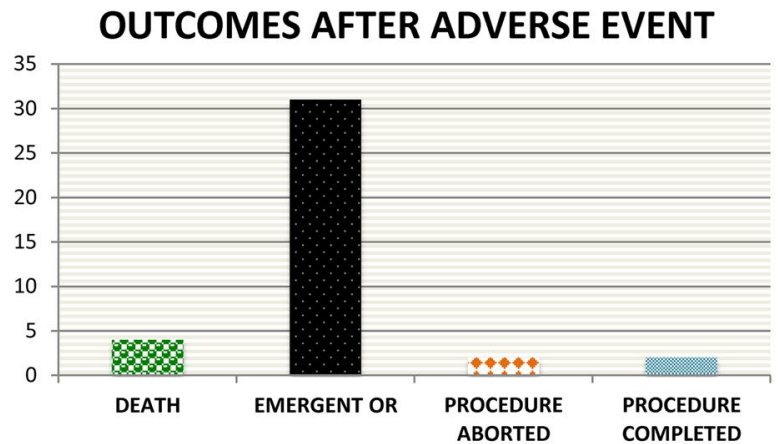

Fig. 5 FDA MAUDE database review. a Types and frequencies of reported adverse events. b Outcomes after an adverse event; VT ventricular tachycardia, LAC laceration, PERF perforation, OR operating room

suture left behind. Device embolization, noted in $1.2 \%$ of patients in the PREVAIL trial of the WATCHMAN device, is not observed with LARIAT LAAO and late device erosion is not a concern (Holmes et al. 2014). Intriguingly, involution of the LAA has been noted on $\mathrm{CT}$ imaging following LARIAT ligation and as early as 4 weeks post-implant on autopsy findings, which may have a desirable impact on the long-term durability of this approach (Massumi et al. 2013; Ellis et al. 2015). LARIAT LAAO results in electrical isolation of the LAA, with post-procedural reduction in AF burden noted as well as increased maintenance of NSR observed when performed in conjunction with pulmonary vein isolation (Han et al. 2014; Afzal et al. 2015; Badhwar et al. 2015). In the PROTECT-AF and CAP registries of the WATCHMAN device, a less than $5 \mathrm{~mm}$ peri-device residual leak into the appendage defined procedural success, whereas several LARIAT series demonstrate no or minimal residual jet with a similar rate of procedural success (Bartus et al. 2013; Massumi et al. 2013; Miller et al. 2014; Holmes et al. 2009; Reddy et al. 2011). In case series, 6.25-35.7 \% of patients screened for LARIAT LAAO are excluded due to anatomical exclusions, while in the PROTECT-AF experience of the WATCHMAN device, $38.9 \%$ of patients screened for device placement were excluded for clinical and echocardiographic reasons, suggesting that a complement of LAAO approaches may be suitable to serve a clinically an anatomically diverse population of AF patients (Stone et al. 2013; Bartus et al. 2011, 2013; Holmes et al. 2009).

Widespread adoption of LARIAT LAAO is limited by lack of efficacy data, with utilization rationalized by presumed efficacy extrapolated from other appendage exclusion mechanisms, and minimal data regarding rate of long-term thrombotic events and procedural complications. Theoretically, AC after LARIAT LAAO is not required as only an epicardial suture is retained, however in the cumulative published experience, a TIA/CVA was observed in $1.8 \%$ of patients in follow-up (Table 5) and $\mathrm{AC}$ or anti-platelet therapy was continued in $55 \%$ of patients in the controlled Bartus et al. series, reflecting uncertainty regarding residual thrombo-embolic risk in the absence of randomized trial data (Bartus et al. 2013). Comparatively, AC therapy was discontinued in most patients 45 days after WATCHMAN implant in the PREVAIL and PROTECT-AF trials (Holmes et al. 2009, 2014). Several case reports detail thrombus at the site of the LAA orifice on surveillance imaging following LARIAT LAAO and thrombus was noted in $2.2 \%$ of cases in the cumulative published experience (Table 3; Fig. 6a) (Price and Gibson 2014; Bartus et al. 2013; Briceno et al. 2013; Koranne et al. 2015; Giedrimas et al. 2013; Baker et al. 2013). Thrombus formation results from an inflammatory environment at the ligation site, epithelial denuding at the LAA orifice during balloon catheter retrieval and sub-optimal suture deployment with a remnant thrombus-promoting static LAA chamber (Fig. 6b) (Bartus et al. 2014). Additionally, recurrent LA-LAA communication after initial successful LARIAT LAAO can result from knot-loosening and tissue necrosis at the suture site and is another mechanism of thrombo-embolic complication. In case reports, late leaks have been treated successfully with alternate LAAO devices as repeat LARIAT ligation is not typically pursued due to potential pericardial adhesions developed after the initial procedure (Yeow et al. 2013; Mosley et al. 2014; Di Biase et al. 2013; Pillai et al. 2014). The implications of residual leak are unknown, however in a review of 259 patients who underwent LARIAT ligation, $14 \%$ were noted to have recurrent LA-LAA communication at 1 year, compared with $21 \%$ in patients undergoing WATCHMAN endocardial occlusion. Most commonly recurrent communication was of a central or 'gunny sack' 

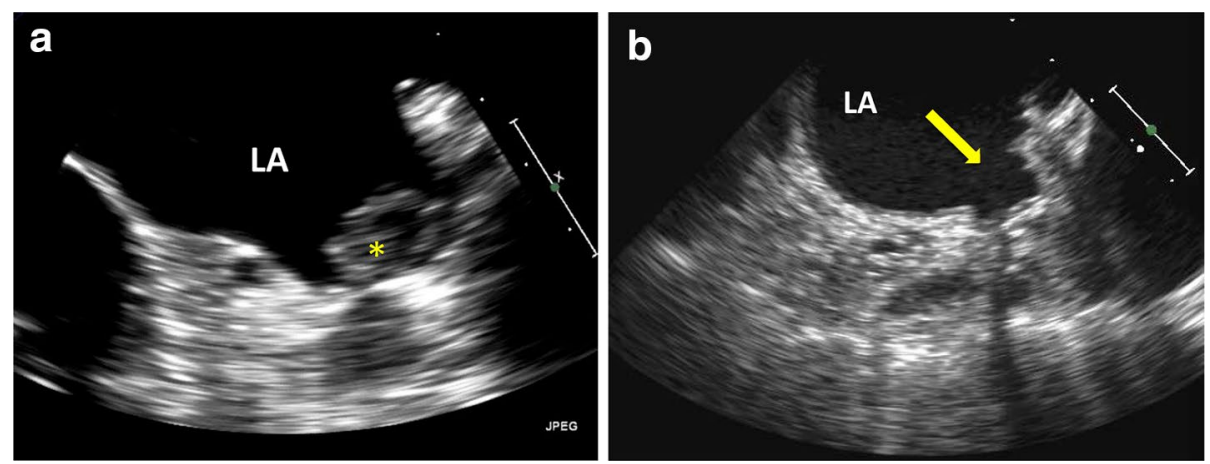

Fig. 6 Complications noted during follow-up TEE after LARIAT LAAO. a Thrombus at the site of LAA ligation (*). b Residual LAA stump with pectinate muscle in LA (arrow)

pattern, with no link with CVA observed (Pillarisetti et al. 2015). Additionally, in a post hoc and underpowered analysis of the PROTECT-AF trial, increased thromboembolic events were not noted in follow-up of patients with persistent peri-device flow with the WATCHMAN device (Viles-Gonzalez et al. 2012).

The incidence of peri-procedural complications during LARIAT LAAO is poorly delineated and derived from one controlled trial evaluating the device in 92 subjects and experience from reported case series. A peri-procedural death rate of $0.3 \%$ is noted in the cumulative published LARIAT experience, however the FDA's MAUDE database reports four procedure-related deaths, likely reflecting publication bias present in reported caseseries (Table 5; Fig. 5). The emergent surgery rate in the cumulative LARIAT experience was $2.4 \%$ (8 patients) compared with 31 reports of emergent surgery in the MAUDE database. Notably, the emergency surgery rate was $1.6 \%$ in the PROTECT-AF trial and $0.4 \%$ in the PREVAIL trial (Holmes et al. 2009, 2014). Uniquely, LARIAT LAAO results in a high rate of pericarditis due to pericardial manipulations and appendage necrosis and is also linked to the development of pleural effusions. Long-term implications of pericardial manipulation, inflammation and adhesion formation after LARIAT LAAO are not known. Paucity of data regarding realworld rate of procedural complications and the device's exclusively off-label use were critiqued in a recent JAMA review (Holmes et al. 2009; Chatterjee et al. 2015). The device is currently being studied in a multi-center observational trial evaluating procedural complication rate and short-term durability [ClinicalTrials.gov, NCT02059707].

A large, controlled trial of LARIAT LAAO would inform the incidence and mechanisms of various complications of LARIAT LAAO as well as possible means of improving upon these in a systematic fashion. Analysis of the PROTECT-AF trial and Continuing Access Registry of the WATCHMAN device allowed for advancements in operator training as well as device refinements and protocol modifications that resulted in significant improvement in the safety and efficacy of the device (Holmes et al. 2009; Reddy et al. 2013). Further insight into anatomical considerations that would enhance current inclusion and exclusion criteria for LARIAT LAAO could also be obtained by a large-scale trial of the device. Delineation of an optimal AC regimen would inform and standardize post-procedural practice. Establishment of efficacy in reduction of thrombo-embolic events compared with Coumadin or NOACs is an important aim for future investigations and for meaningful comparison with other LAAO systems.

\section{Conclusion}

The LARIAT device is an epicardial approach to LAA ligation, with safety and efficacy studied in small clinical series. Epicardial ligation may have potential advantages over endocardial occlusion such as LAA involution and electrical isolation. True complications rates and procedural strategies to prevent and manage complications, efficacy in reduction of thrombo-embolic events, optimal patient selection and post-procedural AC regimens remain to be delineated for the LARIAT ligation system.

\section{Authors' contributions}

MS conceived of the review and drafted the manuscript. VS participated in drafting the manuscript and revised it critically for intellectual content. MD participated in drafting the manuscript and revised it critically for intellectual content. MP participated in drafting the manuscript and revised it critically for intellectual content as well as provided material for Figures.

\section{Authors' information}

MS is a an Assistant Professor of Medicine at the University of Maryland School of Medicine (UMSOM) and is a practicing interventional cardiologist, performing coronary interventions as well as structural interventions including left atrial appendage ligation with the LARIAT device.

VS is an Assistant Professor of Medicine at the UMSOM a practices clinical electrophysiology including structural interventions such as left atrial appendage ligation with the LARIAT device. 
MD is an Assistant Professor of Medicine at the UMSOM and a practicing cardiac surgeon performing left atrial appendage ligation with the AtriClip device as well as left atrial appendage ligation with the LARIAT device. MP is an Associate Professor of Medicine at the University of San Francisco School of Medicine and a practicing interventional cardiologist performing left atrial appendage exclusion procedures.

\section{Author details}

1 University of Maryland School of Medicine, 110 S. Paca Street; 7N-121, Baltimore, MD 21201, USA. ${ }^{2}$ Scripps Clinic, 10666 N. Torrey Pines Road, La Jolla, CA, USA.

\section{Compliance with ethical guidelines}

\section{Competing interests}

MP reports receipt of consulting honoraria from St. Jude Medical, Boston Scientific, W.L. Gore and Daiichi Sankyo, Accumetrics, AstraZeneca, Janssen Pharmaceuticals. MP has also served as a proctor for Boston Scientific, St. Jude Medical, SentreHeart and W.L. Gore and has received research support from SentreHeart Inc. The other authors (MS, VS, MD) declare that they have no competing interests.

Received: 2 July 2015 Accepted: 28 August 2015

Published online: 17 September 2015

\section{References}

Afzal MR, Kanmanthareddy A, Earnest M, Reddy M, Atkins D, Bommana S et al (2015) Impact of left atrial appendage exclusion using an epicardial ligation system (LARIAT) on atrial fibrillation burden in patients with cardiac implantable electronic devices. Heart Rhythm 12(1):52-59. doi:10.1016/j. hrthm.2014.09.053

Al-Saady NM, Obel OA, Camm AJ (1999) Left atrial appendage: structure, function, and role in thromboembolism. Heart 82(5):547-554

Badhwar N, Lakkireddy D, Kawamura M, Han FT, lyer SK, Moyers BS et al (2015) Sequential percutaneous LAA ligation and pulmonary vein isolation in patients with persistent AF: initial results of a feasibility study. J Cardiovasc Electrophysiol. doi:10.1111/jce.12655

Baker MS, Paul Mounsey J, Gehi AK, Chung EH (2013) Left atrial thrombus after appendage ligation with LARIAT. Heart Rhythm. doi:10.1016/j. hrthm.2013.10.024

Bartus K, Bednarek J, Myc J, Kapelak B, Sadowski J, Lelakowski J et al (2011) Feasibility of closed-chest ligation of the left atrial appendage in humans. Heart Rhythm 8(2):188-193. doi:10.1016/j.hrthm.2010.10.040

Bartus K, Han FT, Bednarek J, Myc J, Kapelak B, Sadowski J et al (2013) Percutaneous left atrial appendage suture ligation using the LARIAT device in patients with atrial fibrillation: initial clinical experience. J Am Coll Cardiol 62(2):108-118. doi:10.1016/j.jacc.2012.06.046

Bartus K, Morelli RL, Szczepanski W, Kapelak B, Sadowski J, Lee RJ (2014) Anatomic analysis of the left atrial appendage after closure with the LARIAT device. Circ Arrhythm Electrophysiol 7(4):764-767. doi:10.1161/CIRCEP.113.001084

Bonow RO, Carabello BA, Chatterjee K, de Leon AC Jr, Faxon DP, Freed MD et al (2008) 2008 Focused update incorporated into the ACC/AHA 2006 guidelines for the management of patients with valvular heart disease: a report of the American College of Cardiology/American Heart Association Task Force on Practice Guidelines (Writing Committee to Revise the 1998 Guidelines for the Management of Patients With Valvular Heart Disease): endorsed by the Society of Cardiovascular Anesthesiologists, Society for Cardiovascular Angiography and Interventions, and Society of Thoracic Surgeons. Circulation 118(15):e523-e661. doi:10.1161/CIRCULATIONAHA.108.190748

Briceno DF, Fernando RR, Laing ST (2013) Left atrial appendage thrombus post LARIAT closure device. Heart Rhythm 11(9):1600-1601. doi:10.1016/j. hrthm.2013.10.053

Chatterjee S, Herrmann HC, Wilensky RL, Hirshfeld J, McCormick D, Frankel DS et al (2015) Safety and procedural success of left atrial appendage exclusion with the lariat device: a systematic review of published reports and analytic review of the FDA MAUDE database. JAMA Intern Med. doi:10.1001/jamainternmed.2015.1513
Connolly SJ, Ezekowitz MD, Yusuf S, Eikelboom J, Oldgren J, Parekh A et al (2009) Dabigatran versus warfarin in patients with atrial fibrillation. N Engl J Med 361(12):1139-1151. doi:10.1056/NEJMoa0905561

Cox JL, Ad N, Palazzo T (1999) Impact of the maze procedure on the stroke rate in patients with atrial fibrillation. J Thorac Cardiovasc Surg 118(5):833-840

Di Biase L, Burkhardt JD, Gibson DN, Natale A (2013) 2D and 3D TEE evaluation of an early reopening of the LARIAT epicardial left atrial appendage closure device. Heart Rhythm 11(6):1087-1088. doi:10.1016/j. hrthm.2013.08.023

Ellis CR, Byrd JM, Scalf SL (2015) Ischemic necrosis of the left atrial appendage at autopsy 4 weeks following epicardial suture ligation via a sub-xiphoid approach (LARIAT). J Interv Card Electrophysiol 43(1):99-100. doi:10.1007/ s10840-015-9993-4

Gafoor S, Franke J, Bertog S, Boehm P, Heuer L, Gonzaga M et al (2014) Left atrial appendage occlusion in octogenarians: short-term and 1-year follow-up. Catheter Cardiovasc Interv 83(5):805-810. doi:10.1002/ccd.25297

Giedrimas E, Lin AC, Knight BP (2013) Left atrial thrombus after appendage closure using LARIAT. Circ Arrhythm Electrophysiol 6(4):e52-e53. doi:10.1161/CIRCEP.113.000532

Go AS, Hylek EM, Borowsky LH, Phillips KA, Selby JV, Singer DE (1999) Warfarin use among ambulatory patients with nonvalvular atrial fibrillation: the anticoagulation and risk factors in atrial fibrillation (ATRIA) study. Ann Intern Med 131(12):927-934

Granger CB, Alexander JH, McMurray JJ, Lopes RD, Hylek EM, Hanna M et al (2011) Apixaban versus warfarin in patients with atrial fibrillation. N Engl J Med 365(11):981-992. doi:10.1056/NEJMoa1107039

Gunda S, Kanmanthareddy A, Vallakati A, Janga P, Afzal MR, Pillarisetti J et al (2015) Characterization of pleural effusion after left atrial appendage exclusion using Lariat. J Cardiovasc Electrophysiol. doi:10.1111/jce.12648

Han FT, Bartus K, Lakkireddy D, Rojas F, Bednarek J, Kapelak B et al (2014) The effects of LAA ligation on LAA electrical activity. Heart Rhythm 11(5):864-870. doi:10.1016/j.hrthm.2014.01.019

Holmes DR, Reddy VY, Turi ZG, Doshi SK, Sievert H, Buchbinder M et al (2009) Percutaneous closure of the left atrial appendage versus warfarin therapy for prevention of stroke in patients with atrial fibrillation: a randomised non-inferiority trial. Lancet 374(9689):534-542. doi:10.1016/ S0140-6736(09)61343-X

Holmes DR Jr, Kar S, Price MJ, Whisenant B, Sievert H, Doshi SK et al (2014) Prospective randomized evaluation of the Watchman Left Atrial Appendage Closure device in patients with atrial fibrillation versus long-term warfarin therapy: the PREVAIL trial. J Am Coll Cardiol 64(1):1-12. doi:10.1016/j. jacc.2014.04.029

Ismail TF, Panikker S, Markides V, Foran JP, Padley S, Rubens MB et al (2015) CT imaging for left atrial appendage closure: a review and pictorial essay. J Cardiovasc Comput Tomogr 9(2):89-102. doi:10.1016/j.jcct.2015.01.011

January CT, Wann LS, Alpert JS, Calkins H, Cleveland JC Jr, Cigarroa JE et al (2014) 2014 AHA/ACC/HRS guideline for the management of patients with atrial fibrillation: executive summary: a report of the American College of Cardiology/American Heart Association Task Force on practice guidelines and the heart rhythm society. Circulation 130(23):2071-2104. doi:10.1161/CIR.0000000000000040

Kanmanthareddy M, Reddy YM, Vallakati A et al (2014) Embryology and anatomy of the left atrial appendage: why does thrombus form? Interv Cardiol Clin 3:191-202

Katz ES, Tsiamtsiouris T, Applebaum RM, Schwartzbard A, Tunick PA, Kronzon I (2000) Surgical left atrial appendage ligation is frequently incomplete: a transesophageal echocardiograhic study. J Am Coll Cardiol 36(2):468-471

Keating VP, Kolibash CP, Khandheria BK, Bajwa T, Sra J, Kress DC (2014) Left atrial laceration with epicardial ligation device. Ann Thorac Cardiovasc Surg 20(Suppl):904-908. doi:10.5761/atcs.cr.13-00134

Koneru JN, Badhwar N, Ellenbogen KA, Lee RJ (2014) LAA ligation using the LARIAT suture delivery device: tips and tricks for a successful procedure. Heart Rhythm. doi:10.1016/j.hrthm.2014.01.022

Koranne KP, Fernando R, Laing ST (2015) Left atrial thrombus after complete left atrial appendage exclusion with LARIAT device. Catheter Cardiovasc Interv 85(2):E54-E57. doi:10.1002/ccd.25549

Laura DM, Chinitz LA, Aizer A, Holmes DS, Benenstein R, Freedberg RS et al (2014) The role of multimodality imaging in percutaneous left atrial appendage suture ligation with the LARIAT device. J Am Soc Echocardiogr 27(7):699-708. doi:10.1016/j.echo.2014.04.014 
Lee RJ, Bartus K, Yakubov SJ (2010) Catheter-based left atrial appendage (LAA) ligation for the prevention of embolic events arising from the LAA: initial experience in a canine model. Circ Cardiovasc Interv 3(3):224-229. doi:10.1161/CIRCINTERVENTIONS.109.914978

Lip GY, Nieuwlaat R, Pisters R, Lane DA, Crijns HJ (2010) Refining clinical risk stratification for predicting stroke and thromboembolism in atrial fibrillation using a novel risk factor-based approach: the euro heart survey on atrial fibrillation. Chest 137(2):263-272. doi:10.1378/chest.09-1584

Lip GY, Frison L, Halperin JL, Lane DA (2011) Comparative validation of a novel risk score for predicting bleeding risk in anticoagulated patients with atrial fibrillation: the HAS-BLED (Hypertension, Abnormal Renal/Liver Function, Stroke, Bleeding History or Predisposition, Labile INR, Elderly, Drugs/Alcohol Concomitantly) score. J Am Coll Cardiol 57(2):173-180. doi:10.1016/j.jacc.2010.09.024

Massumi A, Chelu MG, Nazeri A, May SA, Afshar-Kharaghan H, Saeed M et al (2013) Initial experience with a novel percutaneous left atrial appendage exclusion device in patients with atrial fibrillation, increased stroke risk, and contraindications to anticoagulation. Am J Cardiol 111(6):869-873. doi:10.1016/j.amjcard.2012.11.061

Miller MA, Gangireddy SR, Doshi SK, Aryana A, Koruth JS, Sennhauser S et al (2014a) Multicenter study on acute and long-term safety and efficacy of percutaneous left atrial appendage closure using an epicardial suture snaring device. Heart Rhythm 11(11):1853-1859. doi:10.1016/j. hrthm.2014.07.032

Miller MA, Gangireddy SR, Doshi SK, Aryana A, Koruth JS, Sennhauser S et al (2014b) Multicenter study on acute and long-term safety and efficacy of percutaneous left atrial appendage closure using an epicardial suture snaring device. Heart Rhythm. doi:10.1016/j.hrthm.2014.07.032

Mosley WJ, Smith MR, Price MJ (2014) Percutaneous management of late leak after lariat transcatheter ligation of the left atrial appendage in patients with atrial fibrillation at high risk for stroke. Catheter Cardiovasc Interv 83(4):664-669. doi:10.1002/ccd.25251

Patel MR, Mahaffey KW, Garg J, Pan G, Singer DE, Hacke W et al (2011) Rivaroxaban versus warfarin in nonvalvular atrial fibrillation. N Engl J Med 365(10):883-891. doi:10.1056/NEJMoa1009638

Patel MB, Rasekh A, Shuraih M, Chelu MG, Bartlett T, Mathuria N et al (2015) Safety and effectiveness of compassionate use of LARIAT(R) device for epicardial ligation of anatomically complex left atrial appendages. J Interv Card Electrophysiol 42(1):11-19. doi:10.1007/s10840-014-9963-2

Pillai AM, Kanmanthareddy A, Earnest M, Reddy M, Ferrell R, Nath J et al (2014) Initial experience with post Lariat left atrial appendage leak closure with Amplatzer septal occluder device and repeat Lariat application. Heart Rhythm 11(11):1877-1883. doi:10.1016/j.hrthm.2014.06.035
Pillarisetti J, Reddy YM, Gunda S, Swarup V, Lee R, Rasekh A et al (2015) Endocardial (watchman) versus epicardial (Lariat) left atrial appendage exclusion devices: understanding the differences in the location and type of leaks and their clinical implications. Heart Rhythm. doi:10.1016/j. hrthm.2015.03.020

Price MJ (2014) Prevention and management of complications of left atrial appendage closure devices. Interv Cardiol Clin 3:301-311

Price M, Gibson D, Yakubov S et al (2014) Early safety and efficacy of percutaneous left atrial appendage suture ligation with the Lariat device. J Am Coll Cardiol 64:565-572

Reddy VY, Holmes D, Doshi SK, Neuzil P, Kar S (2011) Safety of percutaneous left atrial appendage closure: results from the Watchman Left Atrial Appendage System for Embolic Protection in Patients with AF (PROTECT AF) clinical trial and the Continued Access Registry. Circulation 123(4):417-424. doi:10.1161/CIRCULATIONAHA.110.976449

Reddy VY, Doshi SK, Sievert H, Buchbinder M, Neuzil P, Huber K et al (2013) Percutaneous left atrial appendage closure for stroke prophylaxis in patients with atrial fibrillation: 2.3-year follow-up of the PROTECT AF (Watchman left atrial appendage system for embolic protection in patients with atrial fibrillation) trial. Circulation 127(6):720-729. doi:10.1161/ CIRCULATIONAHA.112.114389

Singh SM, Dukkipati SR, d'Avila A, Doshi SK, Reddy VY (2010) Percutaneous left atrial appendage closure with an epicardial suture ligation approach: a prospective randomized pre-clinical feasibility study. Heart Rhythm 7(3):370-376. doi:10.1016/j.hrthm.2009.11.010

Stone D, Byrne T, Pershad A (2013) Early results with the LARIAT device for left atrial appendage exclusion in patients with atrial fibrillation at high risk for stroke and anticoagulation. Catheter Cardiovasc Interv. doi:10.1002/ ccd.25065

Valderrabano M (2014) Pericardial access for lariat left atrial appendage closure. Interv Cardiol Clin 3:281-289

Viles-Gonzalez JF, Kar S, Douglas P, Dukkipati S, Feldman T, Horton R et al (2012) The clinical impact of incomplete left atrial appendage closure with the Watchman Device in patients with atrial fibrillation: a PROTECT AF (Percutaneous Closure of the Left Atrial Appendage Versus Warfarin Therapy for Prevention of Stroke in Patients With Atrial Fibrillation) substudy. J Am Coll Cardiol 59(10):923-929. doi:10.1016/j.jacc.2011.11.028

Yeow WL, Matsumoto T, Kar S (2013) Successful closure of residual leak following LARIAT procedure in a patient with high risk of stroke and hemorrhage. Catheter Cardiovasc Interv 83(4):661-663. doi:10.1002/ccd.25219

\section{Submit your manuscript to a SpringerOpen ${ }^{\odot}$ journal and benefit from:}

- Convenient online submission

- Rigorous peer review

- Immediate publication on acceptance

- Open access: articles freely available online

- High visibility within the field

- Retaining the copyright to your article

Submit your next manuscript at $>$ springeropen.com 